\title{
Penerapan Model Experiential Learning Berbasis Local Wisdom terhadap Kreativitas Siswa dalam Pembelajaran Materi SBdP Kelas IV SD Negeri 10 Sembawa
}

\author{
Tutut Agustianza ${ }^{1}$, Erfan Ramadhani ${ }^{2}$, Ali Fakhrudin ${ }^{3}$ \\ 1, 2, 3 (Universitas PGRI Palembang, Indonesia).
}
* Corresponding Author. E-mail: ${ }^{1}$ agustianzatutut@gmail.com ${ }^{2}$ erfan@univpgri-palembang.ac.id 3alifakhrudin12@univpgri-palembang.ac.id

\begin{abstract}
Abstrak
Tujuan penelitian ini adalah untuk: 1) mengetahui bagaimana kreativitas siswa pada pembelajaran SBdP sebelum diberikan perlakuan menggunakan model pembelajaran experiential learning di, 2) mengetahui bagaimana kreativitas siswa pada pembelajaran SBdP setelah diberikan perlakuan menggunakan model pembelajaran experiential learning, 3) mengetahui Apakah model pembelajaran experiential learning efektif terhadap kreativitas siswa pada pembelajaran SBdP. Metode dalam penelitian yang digunakan Quasi Experimen dengan desain penelitian One-Group Pretest-Posttest Design. Populasi dan sampel penelitian, yaitu seluruh siswa SD Negeri 10 Sembawa dengan sampel dalam penelitian ini adalah kelas IV dengan jumlah laki-laki 21 orang dan perempuan berjumlah 22 orang. Hasil penelitian menunjukkan bahwa: 1) Kreativitas siswa pada pembelajaran SBdP sebelum diberikan perlakuan menggunakan model pembelajaran experiential learning rata-rata adalah 29,74 dengan kriteria Cukup Kreatif sebanyak 24 siswa (55,8\%); dengan kriteria Tidak Kreatif sebanyak 19 siswa (44,2\%); serta tidak ada siswa dengan kriteria Sangat Kreatif dan Kreatif, 2) Kreativitas siswa pada pembelajaran SBdP setelah diberikan perlakuan menggunakan model pembelajaran experiential learning rata-rata adalah 70,14 kriteria Sangat Kreatif sebanyak 2 siswa (4,7\%); dengan kriteria Kreatif sebanyak 37 siswa (86,0\%); dengan kriteria Cukup Kreatif sebanyak 4 siswa (9,3\%); serta tidak ada siswa dengan kriteria Tidak Kreatif, 3) Model pembelajaran expriential learning efektif terhadap kreativitas siswa dalam pembelajaran materi SBdP dengan nilai $t_{\text {hitung }}$ sebesar 7,418 dan nilai $t_{\text {tabel }}$ sebesar 2.017, maka Ho ditolak dan Ha diterima.
\end{abstract}

Kata kunci: model experiential learning, local wisdom, model pembelajaran

\begin{abstract}
The aims of this study were to: 1) find out how the creativity of students in SBdP learning was before being treated using the experiential learning model, 2) find out how the creativity of students in SBdP learning was after being treated using the experiential learning model, 3) find out whether the experiential learning model was effective learning on students' creativity in SBdP learning. The research method used is Quasi Experiment with a research design of One-Group Pretest-Posttest Design. The population and sample of the study were all students of SD Negeri 10 Sembawa. The sample in this study was class IV with 21 males and 22 females. The results showed that: 1) The average student creativity in SBdP learning before being treated using the experiential learning model was 29.74 with the criteria of Creative Enough as many as 24 students (55.8\%); with criteria Not Creative as many as 19 students (44.2\%); and there are no students with Very Creative and Creative criteria, 2) Student creativity in SBdP learning after being given treatment using the experiential learning model on average is 70.14 Very Creative criteria as many as 2 students (4.7\%); with Creative criteria as many as 37 students (86.0\%); with the criteria of Creative Enough as many as 4 students (9.3\%); and there are no students with non-creative criteria, 3) the expriential learning model is effective on students' creativity in learning the SBdP material with a tcount of 7.418 and a ttable of 2,017, then Ho is rejected and Ha is accepted.
\end{abstract}

Keywords: experiential learning model, local wisdom, learning model

\section{Pendahuluan}

Salah satu mata pelajaran yang diajarkan di sekolah adalah mata pelajaran
Seni Budaya dan Prakarya (SBdP). Pembelajaran yang diterima siswa salah satunya Seni Budaya dan Prakarya (SBdP), 
bahwa pembelajaran Seni Budaya dan Prakarya (SBdP) memiliki muatan yang berhubungan dengan kreativitas, diantara nya seni tari sebagai olah tubuh, seni musik sebagai olah suara, seni rupa sebagai olah terapan dan keterampilan lainnya (Susanto, 2013:186).

Menurut Trianto (2011:136) mengemukakan pendapatnya adalah suatu kumpulan teori yang sistematis, penerapannya secara umum terbatas pada gejala-gejala alam lahir dan berkembang melalui metode ilmiah seperti observasi dan eksperimen yang menuntut sikap ilmiah seperti rasa ingin tahu, terbuka, jujur, dan sebagainya. Seni Budaya dan Prakarya (SBdP) bukanlah ilmu pengetahuan yang diperoleh melalui kegiatan pembelajaran yang berorientasi pada upaya mengembang kan dan menguji daya ingat siswa sehingga kemampuan berpikir siswa direduksi dan sekedar dipahami sebagai kemampuan untuk mengingat. Proses pembelajaran Seni Budaya dan Prakarya (SBdP) ditekankan pada pemberian pengalaman langsung untuk mengembangkan kompetensi agar siswa menjelajahi dan memahami alam sekitar terjadi secara alamiah, hal ini membantu siswa untuk memperoleh pemahaman yang lebih mendalam.

Pembelajaran yang berorientasi pada pengalaman siswa sangat relevan untuk dilaksanakan melalui pembelajara Seni Budaya dan Prakarya (SBdP). Pengalaman belajar menurut Suyono \& Hariyanto (2014:105) merupakan salah satu kegiatan pembelajaran berpandang kontrukvisme. Proses pembelajaran konstrukvisme secara garis besar merefleksikan pengalaman dan mengkonstruksi pengetahuan pemahaman tentang alam di sekitar manusia. Pemilihan perangkat pembelajaran yang sesuai diperlukan untuk mendukung proses pembelajaran yang mampu memberikan pengalaman belajar yang konkret kepada siswa. Perangkat pembelajaran yang dimaksud adalah model pembelajaran.

Pemilihan model pembelajaran merupakan salah satu cara dalam usaha menciptakan suasana belajar yang dikehendaki. Guru mempunyai peranan yang penting dalam menciptakan suasana belajar yang dapat memberikan kesempatan kepada siswa untuk memperoleh pengalaman belajar yang nyata. Guru harus bisa memilih model pembelajaran yang tepat agar tujuan pembelajaran bisa dicapai dengan berhasil.

Salah satu model pembelajaran berbasis pengalaman yang memberi kebermaknaan pada proses pembalajaran terhadap siswa adalah model experiential learning. Kolb (1984) berpendapat bahwa pembelajaran dengan model experiential learning merupakan proses di mana pengetahuan diperoleh melalui transformasi pengalaman. Belajar dengan berdasarkan pengalaman akan lebih terpusat pada pengalaman belajar siswa yang bersifat terbuka dan mampu membimbing dirinya sendiri.

SD Negeri 10 Sembawa merupakan salah satu sekolah di Desa Pulau harapan Kecamatan Sembawa. SD Negeri 10 Sembawa terletak di lokasi yang memiliki goegrafis alam berupa hutan dan persawahan. Kaitannya SD Negeri 10 Sembawa dengan model experiential learning ini, dari observasi awal yang dilakukan bersamaan dengan kegiatan KKN (Kuliah Kerja Nyata) diketahui yang dilakukan di SD Negeri 10 Sembawa belum terlihat kreatifitas siswa dalam pembelajaran SBdP materi kerajinan tangan.

Potensi lingkungan alam sekitar SD Negeri 10 Sembawa yang berupa hutan dan persawahan tersebut belum dimanfaatkan secara maksimal dalam proses pembelajaran, khususnya pada proses pembelajaran Seni Budaya dan Prakarya (SBdP). Potensi alam tersebut sangat disayangkan jika tidak dimanfaatkan sebagai wahana belajar Seni Budaya dan Prakarya (SBdP) bagi siswa. Kondisi alam yang berupa hutan dan persawahan tersebut merupakan wahana belajar yang alami dan konkret sebagai objek pemebelajaranSeni Budaya dan Prakarya (SBdP). Proses pembelajaran yang melibatkan pengalaman 
langsung dan objek belajar yang alami dan konkret bagi siswa membuat proses pembelajaran lebih bermakna.

Proses pembelajaran yang bermakna membawa dampak yang baik bagi prestasi belajar siswa. Kebermaknaan proses pembelajaran menjadikan siswa lebih mudah dalam menangkap materi pembelajaran. Menurut Wijayanti (2009:74) mengungkapkan bahwa sebuah pembelajaran lebih bermakna adalah proses pembelajaran yang membangun makna (input), kemudian prosesnya melalui struktur kognitif, sehingga akan berkesan lama dalam ingatan/memori (terjadi rekonstruksi). Pembelajaran yang bermakna melalui kegiatan yang nyata akan memudahkan siswa dalam memahami materi pelajaran. Selanjutnya pemahaman materi yang baik oleh siswa dapat membantu siswa dalam pencapaian prestasi belajar yang optimal. Prestasi belajar merupakan hasil belajar siswa dalam aspek kognitif, sehingga proses pembelajaran yang bermakna berdampak positif terhadap aspek kognitif siswa juga akan meningkatkan prestasi belajar siswa.

Berdasarkan hasil observasi saat mengikuti Kuliah Kerja Nyata (KKN) selama berjalan kurang lebih satu bulan di SD Negeri 10 Sembawa dapat dinyatakan kemampuan keaktifan dan kemampuan kekreatifan siswa masih belum efisien dalam pembelajaran SBdP materi kerajinan tangan. Pernyataan ini dibuktikan dengan seorang guru yang hanya menyampaikan materi dalam bentuk teori saja serta dalam proses pembelajaran guru masih menggunakan metode konvensional tanpa adanya praktek.

Tentunya hal tersebut hanya menunjukkan proses pembelajaran yang masih bersifat satu arah dan belum mengarah pada student centered sehingga pembelajaran lebih mengutamakan suatu produk dari pada proses dan masih didominasinya pembelajaran dengan menggunakan metode ceramah.

Melalui beberapa permasalahanpermasalahan di atas, dapat dilakukan upaya untuk mengatasi permasalahanpermasalahan tersebut adalah dengan model pembelajaran experiential learning. Model experiential learning dapat disebut juga dengan gaya belajar di luar ruangan, artinya pembelajaran yang akan mengaktifkan pembelajaran untuk dapat membangun pengetahuan dan keterampilan melalui pengalaman secara langsung dengan program pendidikan yang memanfaatkan pengalaman dunia nyata untuk mencapai tujuan belajarnya.

Kolb (2015: 128) mengemukakan pendapatnya proses perubahan yang menggunakan pengalaman sebagai landasan dalam menetapkan pendidikan formal.

Berdasarkan latar belakang dan batasan masalah diatas, maka rumusan masalah dalam penelitian ini adalah:

1) Bagaimana kreativitas siswa pada pembelajaran SBdP sebelum diberikan perlakuan menggunakan model pembelajaran experiential learning di SD Negeri 10 Sembawa?,

2) Bagaimana kreativitas siswa pada pembelajaran SBdP setelah diberikan perlakuan menggunakan model pembelajaran experiential learning di SD Negeri 10 Sembawa?,

3) Apakah model pembelajaran experiential learning efektif terhadapat kreativitas siswa pada pembelajaran SBdP di SD Negeri 10 Sembawa?.

Berdasarkan rumusan masalah di atas, tujuan dari penelitian ini adalah:

1) Untuk mengetahui bagaimana kreativitas siswa pada pembelajaran SBdP sebelum diberikan perlakuan menggunakan model pembelajaran experiential learning di SD Negeri 10 Sembawa.

2) Untuk mengetahui bagaimana kreativitas siswa pada pembelajaran SBdP setelah diberikan perlakuan menggunakan model pembelajaran experiential learning di SD Negeri 10 Sembawa.

3) Untuk mengetahui Apakah model pembelajaran experiential learning 
efektif terhadap kreativitas siswa pada pembelajaran SBdP di SD Negeri 10 Sembawa.

\section{Metode}

Metode penelitian diartikan sebagai metode penelitian yang digunakan untuk mencari pengaruh perlakuan tertentu terhadap yang lain dalam kondisi yang terkendalikan, Sugiyono (2016:72) Metode yang digunakan dalam penelitian ini adalah Quasi Experimen dengan desain penelitian One-Group Pretest-Posttest Design, karena dalam penelitian ini hanya menggunakan satu kelas. Dalam satu kelas sebelum dikenai perlakuan intervensi terlebih dahulu, siswa diberikan pretest yang bertujuan mengetahui keadaan awal dari masing-masing siswa dalam proses pembelajaran materi SBdP.

Mengenai uji coba yang akan dilakukan pada penelitian ini, One-Group Pretest-Posttest Design merupakan salah satu design dari pra-experimental designs (nondesigns) karena pada desain ini terdapat pretest, sebelum diberi perlakuan Sugiyono (2016: 74). Desain ini dapat digambarkan seperti berikut.

$$
\mathrm{O}_{1} \rightarrow \mathrm{X} \rightarrow \mathrm{O}_{2}
$$

Gambar 3.1 Desain Penelitian One-Group Pretest-Posttest Design

Keterangan :

$\mathrm{O}_{1}$ : Nilai pretest kreativitas siswa dalam Pembelajaran materi SBdP (sebelum diberikan perlakuan).

$\mathrm{O}_{2}$ : Nilai posttest kreativitas siswa dalam Pembelajaran materi SBdP (sesudah diberikan perlakuan).

$\mathrm{X}$ : Perlakuan dengan menggunakan model pembelajaran experiential learning.

Populasi dan sampel penelitian, yaitu seluruh SD Negeri 10 Sembawa tahun pelajaran 2021/2022 yang terdiri dari dua kelas dengan sampel dalam penelitian ini adalah kelas IV SD Negeri10 Sembawa dengan jumlah laki-laki 21 orang dan perempuan berjumlah 22 orang. Teknik tes dalam penelitian ini adalah pretest dan posttest secara langsung tanpa sumber dari guru kelas. Dalam penelitian ini bentuk tes yang akan digunakan adalah tes praktik secara langsung dikelas

Teknik analisis data dalam penelitian ini untuk mengetahui tingkatan kemampuan kreativitas siswa dalam pembelajaran materi SBdP dilakukan analisis terhadap hasil pretest dan posttest berdasarkan pengujian hipotesis sebagai berikut:

a) Uji Normalitas Data.

Untuk mengetahui peningkatan kemampuan menulis siswa dilakukan analisis terhadap hasil pretest dan posttest. Dalam penelitian ini pengambilan data dengan menggunakan data pretest dan posttest, maka analisis yang dilakukan dengan menggunakan rumus uji normalitas Lilliefors dengan taraf siginifikansi $(\alpha=0,05)$ (Sudjana, 2008: 466). Kriteria pengujian sebagai berikut:

1) Jika $L_{o}<L$, maka hasil populasi ber distribusi normal.

2) Jika $L_{o}>L$, maka populasi tidak ber distribusi normal.

b) Uji Homogenitas Data.

Uji homogenitas adalah suatu uji yang dilakukan untuk mengetahui bahwa dua atau lebih kelompok data sampel berasal dari populasi yang memiliki varians sama (homogen). Data yang dilakukan pengujian dikatakan homogen berdasarkan nilai signifikansinya. Jika nilai Signifikansi > 0,05 menunjukkan kelompok data berasal dari populasi yang memiliki varians yang sama (homogen) dan jika nilai Signifikansi $<0,05$ menunjukkan masing-masing kelompok data berasal dari populasi dengan varians yang berbeda (tidak homogen) (Jainuri, 2019:40).

c) Data Kemampuan Kreatifitas Siswa. Data pelaksanaan pembelajaran dapat 
Jurnal Edumaspul, 5 (2), Year 2021 - 356

(Tutut Agustianza, Erfan Ramadhani, Ali Fakhrudin)

diambil aktifitas dengan menggunakan lembar kemampuan kreatifitas siswa yang berbentuk cheklist selama mengikuti pembelajaran materi SBdP. Selanjutnya dianalisis dengan menggunakan rumus persentase. Menurut Sudijono (2004:43) rumus persentase sebagai berikut.

$$
\mathrm{P}=\frac{\mathrm{f}}{\mathrm{N}} \times 100 \%
$$

Keterangan:

$\mathrm{P}$ : Angka persentase.

F : Frekuensi yang disedang dicari persentasenya.

$\mathrm{N}$ : Number of Cases (Jumlah frekuensi atau banyaknya individu).

Selanjutnya menentukan penilaian kemampuan kreatifitas siswa.

Keterangan :

$$
\begin{array}{ll}
80-100 \% & =\text { Sangat Kreatif } \\
60-79 \% & =\text { Kreatif } \\
30-59 \% & =\text { Cukup Kreatif } \\
0-29 \% & =\text { Tidak Kreatif }
\end{array}
$$

Indikator penilaian kemampuan kreatifitas siswa dikatakan Sangat Kreatif jika dalam kegiatan belajar mendapatkan nilai $\geq 81 \%$.

d) Uji Hipotesis.

Uji hipotesis ialah metode untuk membuktikan keputusan hipotesis diterima atau ditolak dari kegiatan analisis data. Dalam penelitian ini untuk mengetahui tingkatan kemampuan kreativitas siswa dalam pembelajaran materi SBdP dilakukan analisis terhadap hasil pretest dan posttest menggunakan rumus uji- $t$ Arikunto (2010:125) sebagai berikut.

Keterangan:

$$
t=\frac{\mathrm{Md}}{\sqrt{\frac{\sum x^{2} d}{n(n-1)}}}
$$

Md : Mean dari perbedaan Pre-Test dan Post - Test

d : Deviasi masing-masing subjek (d-Md)

$\sum \mathrm{x} 2 \mathrm{~d}$ : Jumlah kuadrat deviasi

$\mathrm{n} \quad$ : Jumlah subjek pada sampel d : Ditentukan dengan n-1

Adapun kriteria pengambilan keputusan adalah sebagai berikut:

1) Jika $>$ maka Ha diterima.

2) Jika $<$ maka Ho ditolak.

\section{Hasil dan Pembahasan}

\section{1) Hasil Penelitian Pada Tes Awal} (Prestest)

Hasil penelitian pada tes awal (prestest) merupakan hasil yang diberikan perlakuan dalam pembelajaran materi SBdP secara konvensional. Metode konvensional merupakan proses pembelajaran yang lebih banyak didominasi gurunya sebagai "pentransfer ilmu", sementara siswa lebih pasif sebagai "penerima" ilmu. Dalam pembelajaran materi SBdP dalam pembuatan frame bingkai dari kardus bekas, metode konvensional ditandai dengan ceramah yang diiringi dengan penjelasan serta latihan, yaitu pembuatan frame bingkai dari kardus bekas dengan aspek penilaian, yaitu 1) Persiapan, 2) Inkubasi, 3) Iluminasi, dan 4) Verifikasi.

Setelah pembelajaran materi SBdP kemudian dilakukan tes awal, yaitu berupa pembuatan frame bingkai dari kardus bekas dengan subjek pada tes awal sebanyak 43 orang siswa. Hasil nilai tes awal (prestest) siswa dalam pembuatan frame bingkai dari kardus bekas, siswa dengan nilai tertinggi adalah 47; nilai terendah sebesar 21; dan nilai rata-rata adalah 29,74 .

Berdasarkan hasil tes menunjukkan bahwa hasil pada tes awal (prestest) masih banyak siswa yang belum kreatif dalam pembuatan frame bingkai dari kardus bekas. Untuk lebih jelasnya dapat dilihat pada tabel distribusi frekuensi nilai tes awal (prestest) siswa kelas IV SD Negeri 10 Sembawa.

Tabel 1. Distribusi Frekuensi Nilai Tes Awal (Prestest) Siswa Kelas IV SD Negeri 10 Sembawa

\begin{tabular}{|c|c|c|}
\hline Kriteria & $\begin{array}{c}\text { Frekuensi } \\
(\text { F) }\end{array}$ & $\begin{array}{c}\text { Persentase } \\
(\mathbf{\%})\end{array}$ \\
\hline Sangat & 0 & 0,0 \\
\hline
\end{tabular}




\begin{tabular}{|c|c|c|}
\hline Kreatif & & \\
\hline Kreatif & 0 & 0,0 \\
\hline $\begin{array}{c}\text { Cukup } \\
\text { Kreatif }\end{array}$ & 24 & 55,8 \\
\hline $\begin{array}{c}\text { Tidak } \\
\text { Kreatif }\end{array}$ & 19 & 44,2 \\
\hline Jumlah & $\mathbf{4 3}$ & $\mathbf{1 0 0}$ \\
\hline
\end{tabular}

(Sumber: Data Diolah dari Lampiran 2, Tahun 2021).

Berdasarkan tabel di atas menunjukkan bahwa distribusi frekuensi pada saat tes awal (prestest) siswa kelas IV SD Negeri 10 Sembawa diperoleh nilai dengan kriteria Cukup Kreatif sebanyak 24 siswa atau 55,8\%; dengan kriteria Tidak Kreatif sebanyak 19 siswa atau 44,2\%; serta tidak ada siswa dengan kriteria Sangat Kreatif dan Kreatif. Tabel distribusi frekuensi tersebut dapat disajikan dalam bentuk histogram sebagai berikut.

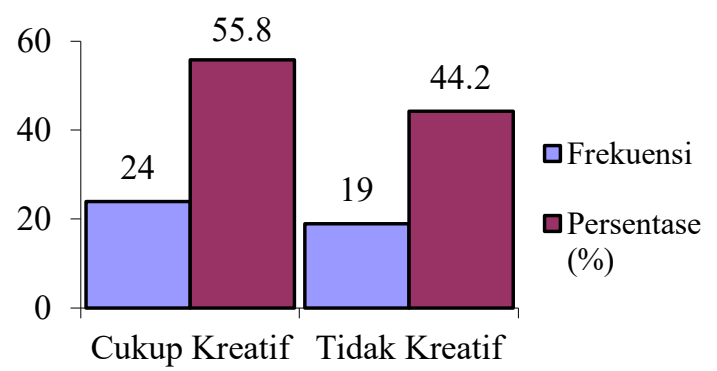

Gambar 1. Histogram Nilai Tes Awal

Berdasarkan hasil di atas, dapat peneliti simpulkan bahwa kreativitas siswa dalam pembuatan frame bingkai dari kardus bekas masih banyak siswa yang tidak kreatif. Dengan demikian, perlu diadakan perbaikan atau tindakan agar diperoleh hasil yang meningkat, yaitu dengan pemberian suatu model pembelajaran. Salah satu model pembelajaran yang dapat meningkatkan kreativitas, yaitu model experiential learning.

\section{2) Hasil Penelitian Pada Tes Akhir (Posttest)}

Setelah pembelajaran materi SBdP kemudian dengan diterapkannya model experiential learning dilakukan tes akhir, yaitu berupa pembuatan frame bingkai dari kardus bekas dengan subjek pada tes awal sebanyak 43 orang siswa. Hasil nilai tes akhir (posttest) siswa dalam pembuatan frame bingkai dari kardus bekas, siswa dengan nilai tertinggi adalah 84; nilai terendah sebesar 49; dan nilai rata-rata adalah 70,14.

Berdasarkan tabel di atas menunjukkan bahwa hasil pada tes akhir (posttest) sudah banyak siswa yang kreatif dalam pembuatan frame bingkai dari kardus bekas dengan diterapkannya model experiential learning. Untuk lebih jelasnya dapat dilihat pada tabel distribusi frekuensi nilai tes akhir (posttest) siswa kelas IV SD Negeri 10 Sembawa.

Tabel 2. Distribusi Frekuensi Nilai Tes Akhir (Posttest) Siswa Kelas IV SD Negeri 10 Sembawa

\begin{tabular}{|c|c|c|}
\hline Kriteria & $\begin{array}{c}\text { Frekuensi } \\
(\mathbf{F})\end{array}$ & $\begin{array}{c}\text { Persentase } \\
(\%)\end{array}$ \\
\hline Sangat Kreatif & 2 & 4,7 \\
\hline Kreatif & 37 & 86,0 \\
\hline Cukup Kreatif & 4 & 9,3 \\
\hline Tidak Kreatif & 0 & 0,0 \\
\hline Jumlah & $\mathbf{4 3}$ & $\mathbf{1 0 0}$ \\
\hline
\end{tabular}

(Sumber: Data Diolah dari Lampiran 3, Tahun 2021).

Berdasarkan tabel di atas menunjukkan bahwa distribusi frekuensi pada saat tes akhir (posttest) siswa kelas IV SD Negeri 10 Sembawa diperoleh nilai dengan kriteria Sangat Kreatif sebanyak 2 siswa atau 4,7\%; dengan kriteria Kreatif sebanyak 37 siswa atau 86,0\%; dengan kriteria Cukup Kreatif sebanyak 4 siswa atau 9,3\%; serta tidak ada siswa dengan kriteria Tidak Kreatif. Tabel distribusi frekuensi tersebut dapat disajikan dalam bentuk histogram sebagai beriku. 
Jurnal Edumaspul, 5 (2), Year 2021 - 358

(Tutut Agustianza, Erfan Ramadhani, Ali Fakhrudin)

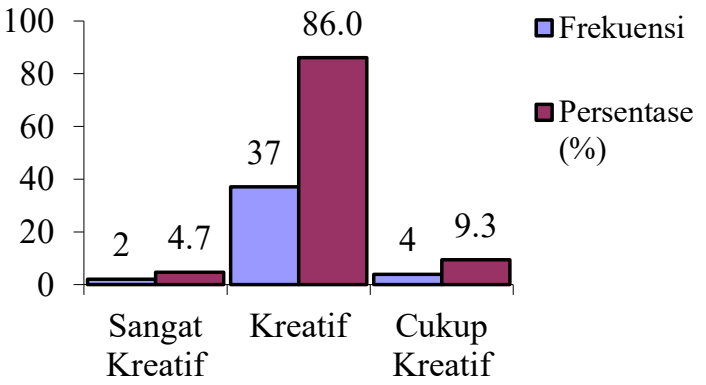

Gambar 2. Histogram Nilai Tes Akhir

\section{3) Analisis Data Penelitian}

a) Uji Normalitas Data

Data dapat dikatakan berdistribusi normal apabila harga nilai signifikasi lebih kecil daripada harga alpha $(\alpha) 0,05$. Hasil uji normalitas data nilai tes awal (prestest) data nilai tes akhir (posttest) dapat dilihat pada tabel berikut.

Tabel 3. Hasil Uji Normalitas Data

\begin{tabular}{|c|c|c|}
\hline Nilai & $\begin{array}{c}\text { Nilai } \\
\text { Signifikan }\end{array}$ & Keterangan \\
\cline { 1 - 2 } Tes Awal & 0,000 & \multirow{2}{*}{ Normal } \\
\hline Tes Akhir & 0,000 & \\
\hline
\end{tabular}

(Sumber: Data Diolah SPSS dari Lampiran 4, Tahun 2021).

Berdasarkan tabel di atas menunjukkan bahwa hasil uji normalitas menggunakan uji normalitas Lilliefors pada level Signifikan alpha $(\alpha) 0,05$. Nilai nilai tes awal (prestest) data nilai tes akhir (posttest) adalah berdistribusi normal dimana nilai Sig $<0,05$.

\section{b) Uji Homogenitas Data}

Uji homogenitas adalah suatu uji $\mathrm{i}_{\mathrm{akh}}^{\text {-Te }}$ yang dilakukan untuk mengetahui bahwa dua atau lebih kelompok data sampel berasal dari populasi yang memiliki varians sama (homogen). Hasil uji homogenitas data nilai tes awal (prestest) data nilai tes akhir (posttest) dapat dilihat pada tabel berikut.

Tabel 4. Hasil Uji Homogenitas Data

\begin{tabular}{|c|c|c|}
\hline Nilai & $\begin{array}{c}\text { Nilai } \\
\text { Signifikan }\end{array}$ & Keterangan \\
\hline Tes Awal &, 750 & \multirow{2}{*}{ Homogen } \\
\hline Tes Akhir &, 098 & \\
\hline
\end{tabular}

(Sumber: Data Diolah SPSS dari Lampiran
4, Tahun 2021).

Dari tabel output di atas dapat diketahui nilai Sig. tes awal sebesar 0,750 dan Sig. tes akhir sebesar 0,098. Karena nilai Sig. $>0,05$ maka dapat disimpulkan bahwa kedua kelompok data mempunyai varian sama atau homogen.

\section{c) Uji Hipotesis}

Untuk menguji hipotesis efektif atau tidaknya model pembelajaran expriential learning terhadap kreativitas siswa dalam pembelajaran materi SBdP di SD Negeri 10 Sembawa, maka dirumuskan sebagai berikut.

Ho: Model pembelajaran expriential learning tidak efektif terhadap kreativitas siswa dalam pembelajaran materi SBdP di SD Negeri 10 Sembawa.

Ha : Model pembelajaran expriential learning efektif terhadap kreativitas siswa dalam pembelajaran materi SBdP di SD Negeri 10 Sembawa.

Kaidah keputusan:

Jika, $t_{\text {hitung }}>\mathrm{t}_{\text {tabel}}$; maka Ha diterima.

Jika, $\mathrm{t}_{\text {hitung }}<\mathrm{t}_{\text {tabel }}$; maka Ho diterima.

Tabel 5. Hasil Uji Hipotesis

\begin{tabular}{|c|c|c|c|c|c|c|c|c|}
\hline & \multicolumn{5}{|c|}{ Paired Differences } & \multirow[b]{3}{*}{$\mathrm{t}$} & \multirow[b]{3}{*}{ df } & \multirow{3}{*}{$\begin{array}{l}\text { Sig. } \\
(2- \\
\text { taile } \\
\text { d) }\end{array}$} \\
\hline & \multirow{2}{*}{$\begin{array}{l}\mathrm{M} \\
\mathrm{e} \\
\mathrm{a} \\
\mathrm{n}\end{array}$} & \multirow{2}{*}{$\begin{array}{l}\text { Std. } \\
\text { Devia } \\
\text { tion }\end{array}$} & \multirow{2}{*}{$\begin{array}{l}\text { Std. } \\
\text { Error } \\
\text { Mean }\end{array}$} & \multicolumn{2}{|c|}{$\begin{array}{l}95 \% \text { Confidence } \\
\text { Interval of the } \\
\text { Difference }\end{array}$} & & & \\
\hline & & & & $\begin{array}{c}\text { Batas } \\
\text { Atas }\end{array}$ & $\begin{array}{c}\text { Batas } \\
\text { Bawah }\end{array}$ & & & \\
\hline $\begin{array}{l}\text { Tes } \\
\text { awal } \\
\text {-Tes } \\
\text { akhir }\end{array}$ & $\begin{array}{l}4 \\
0, \\
3 \\
9 \\
5\end{array}$ & 9,661 & 1,473 & 43,369 & 37,422 & $\begin{array}{l}7 \\
4 \\
1 \\
8\end{array}$ & 42 & ,002 \\
\hline
\end{tabular}

(Sumber: Data Diolah SPSS dari Lampiran 4, Tahun 2021).

Berdasarkan tabel di atas menunjukkan bahwa, nilai Sig. $=0,002$ lebih kecil dari alpha $(\alpha)=0,05$; dengan nilai $t_{\text {hitung }}$ sebesar 7,418 dan nilai nilai $t_{\text {tabel }}$ sebesar 2.017 (lihat Lampiran 5), maka Ho ditolak dan Ha diterima. Berarti model pembelajaran expriential learning efektif terhadap kreativitas siswa dalam pembelajaran materi SBdP di SD Negeri 10 Sembawa. 


\section{Simpulan}

Berdasarkan hasil analisis dan pembahasan yang telah diuraikan pada bab sebelumnya, maka dapat diambil kesimpulan sebagai berikut: 1) Kreativitas siswa pada pembelajaran SBdP sebelum diberikan perlakuan menggunakan model pembelajaran experiential learning berbasis local wisdom terhadap kreativitas siswa dalam pembelajaran materi SBdP kelas IV di SD Negeri 10 Sembawa siswa dengan nilai tertinggi adalah 47 ; nilai terendah sebesar 21; dan nilai rata-rata adalah 29,74. Sedangkan distribusi frekuensi pada saat tes awal (prestest) siswa kelas IV SD Negeri 10 Sembawa diperoleh nilai dengan kriteria Cukup Kreatif sebanyak 24 siswa atau $55,8 \%$; dengan kriteria Tidak Kreatif sebanyak 19 siswa atau 44,2\%; serta tidak ada siswa dengan kriteria Sangat Kreatif dan Kreatif, 2) Kreativitas siswa pada pembelajaran SBdP setelah diberikan perlakuan menggunakan model pembelajaran experiential learning berbasis local wisdom terhadap kreativitas siswa dalam pembelajaran materi SBdP kelas IV di SD Negeri 10 Sembawa siswa dengan nilai tertinggi adalah 84 ; nilai terendah sebesar 49; dan nilai rata-rata adalah 70,14. Sedangkan distribusi frekuensi pada saat tes akhir (posttest) siswa kelas IV SD Negeri 10 Sembawa diperoleh nilai dengan kriteria Sangat Kreatif sebanyak 2 siswa atau 4,7\%; dengan kriteria Kreatif sebanyak 37 siswa atau 86,0\%; dengan kriteria Cukup Kreatif sebanyak 4 siswa atau 9,3\%; serta tidak ada siswa dengan kriteria Tidak Kreatif, 3) Model pembelajaran expriential learning berbasis local wisdom efektif terhadap kreativitas siswa dalam pembelajaran materi SBdP di SD Negeri 10 Sembawa, hal ini dapat dilihat nilai Sig. $=0,002$ lebih kecil dari alpha $(\alpha)=0,05$; dengan nilai $t_{\text {hitung }}$ sebesar 7,418 dan nilai $t_{\text {tabel }}$ sebesar 2.017, maka Ho ditolak dan Ha diterima.

Berdasarkan kesimpulan di atas, dapat disajikan beberapa saran sebagai berikut: 1) Bagi Guru, diharapkan model experiential learning ini dapat dijadikan sebagai salah satu alternatif pemilihan model pembelajaran yang dapat digunakan oleh guru dalam menyampaikan materi SBdP, 2) Bagi Siswa, dalam pembuatan frame bingkai dari kardus bekas diharapkan para siswa bersemangat dalam belajar serta siswa mampu menghasilkan prakarya dan memafaatkan barang bekas lingkungan sekitar, 3) Bagi Sekolah, diharapkan sekolah mengupayakan agar model experiential learning dapat dijadikan alternatif bagi guru-guru kelas dalam pemilihan model pembelajaran di kelas.

\section{Daftar Pustaka}

[1] Arifin, Z. (2017). Evaluasi Pembelajaran. Bandung: Remaja Rosdakarya.

[2] Arikunto. (2014). Metode Penelitian Kuantitatif. Jakarta: Bumi Aksara.

[3] Budiningsih, A. (2012). Belajar dan Pembelajaan. Jakarta: Rineka Cipta.

[4] Dalyono. (2010). Psikologi Pendidikan. Jakarta: Rineka Cipta.

[5] Daniah. (2016). Kearifan Lokal (Local Wisdom) Sebagai Basis Pendidikan Karakter. Pionir: Jurnal Pendidikan, Vol. 5, No. 2, 2016, 114.

[6] Fathurrohman, Muhammad. (2015). Model-Model Pembelajaran Inovatif (Alternatif Desain Pembelajaran yang Menyenangkan). Jogjakarta: Ar-ruzz Media.

[7] Gufron, Nur dan Rini Risnawita S. (2017). Teori Teori Psikologi. Jogjakarta: Ar-ruzz Media.

[8] Hunaepi, H., Firdaus, L., Samsuri, T., Susantini, E., \& Raharjo, R. (2020). Efektifitas Perangat Pembelajaran Inkuiri Terintegrasi Kearifan Lokal Terhadap Keterampilan Berpikir Kritis Mahasiswa. Scholaria: Jurnal Pendidikan Dan Kebudayaan, Vol. 
Jurnal Edumaspul, 5 (2), Year 2021 - 360

(Tutut Agustianza, Erfan Ramadhani, Ali Fakhrudin)

10, No. 3, September 2020, 269281.

[9] Immaniar, B.D., Sumarmi, Astina, I.K. (2019). Pembelajaran Lingkungan Berbasis Kearifan Lokal dengan Model Experiential Learning. Jurnal Pendidikan: Teori, Penelitian, dan Pengembangan, Vol. 4, No. 5, Mei 2019, 648-653.

[10] Kadir.(2017). Statistika Terapan Konsep, Contoh dan Analisis Data dengan Program SPSS/Lisrel dalam Penelitian. Depok: Rajawali Pers.

[11] Kolb, D. (2015). Model Pembelajaran Inovatif. Jogjakarta: Ar-ruzz Media.

[12] Majid. (2015). Model Pembelajaran Efektif. Bandung: Remaja Rosdakarya Offset.

[13] Mulyatiningsih, Endang. (2014). Metode Penelitian Terapan Bidang Pendidikan. Bandung: Alfabeta.

[14] Murfiah, Uum. (2017). Pembelajaran Terpadu (Teori \& Praktik Terbaik di Sekolah). Bandung: Refika Aditama.

[15] Noor. (2011). Metode Penelitian Pendidikan. Bandung: Alfabeta.

[16] Novitasari, Yuni. (2016). Bimbingan dan Konseling Belajar (Akademik). Bandung: Alfabeta.

[17] Nurhikmayati, I. \& Suhendar, A. (2020). Pengembangan Project Based Learning Berbasis Kearifan Lokal Berorientasi pada Kemampuan Berpikir Kreatif dan Kemandirian Belajar. Mosharafa: Jurnal Pendidikan Matematika, Vol. 9, No. 1, Januari 2020, 1-12.
[18] Ramdani, E. (2018). Model Pembelajaran Kontekstual Berbasis Kearifan Lokal sebagai Penguatan Pendidikan Karakter. Jurnal Pendidikan Ilmu-Ilmu Sosial, Vol. 10, No. 1, 1-10.

[19] Rusman. (2017). Belajar dan Pembelajaran Berorientasi Standar Proses Pendidikan. Jakarta: kharisma Putra Utama.

[20] Rohmah, A.A, Suryawan, A.I, Priyanto, I.J. (2019). Penerapan Model Experiential Learning Berbantuan Media Gambar Untuk Meningkatkan Kreativitas Kerajinan Tangan Peserta Didik. Educare, Vol. 17, No. 2, Des. 2019, 119-126.

[21] Rusman. (2015). Pembelajaran Tematik Terpadu (Teori, Praktek dan Penilaian). Jakarta: RajaGrafindo Persada.

[22] Setyosari, P. (2012). Metode Penelitian Pendidikan dan Pengembangan. Jakarta: Kencana.

[23] Sugiyono. (2019). Metode Penelitian Pendidikan. Bandung: Alfabeta.

[24] Sugiyono. (2019). Statistika Untuk Penelitian. Bandung: Alfabeta.

[25] Syah, Muhibbin. (2014). Psikologi Pendidikan Dengan Pendekatan Baru. Bandung: Remaja Rosdakarya.

[26] Winarni, Endang Widi. (2018). Teori dan Praktik Penelitian Kuantitatif, Kualitatif, PTK, $R \& D$. Jakarta: Bumi Aksara.

\section{Profil Penulis}

Tutut Agustianza, lahir di Palembang pada tanggal 24 Agustus 1999, penulis merupakan putri kandung dari pasangan Bapak Zainuddin dan Ibu Neni Triana. Penulis anak ke tiga dari empat bersaudara yaitu Tenti Feneza, Weny Novyanza, dan Wafiza Alrizki. Pada tahun 2010 penulis menyelesaikan pendidikan sekolah dasar di SD Negeri 10 Sembawa. Pada tahun 2014 penulis menyelesaikan sekolah menengah pertama di SMP Negeri 2 Sembawa. Pada tahun 2017 penulis menyelesaikan sekolah menengah atas di SMA Negeri 1 Banyuasin III. Kemudian melanjutkan studi ke perguruan tinggi di Universitas PGRI Palembang. 